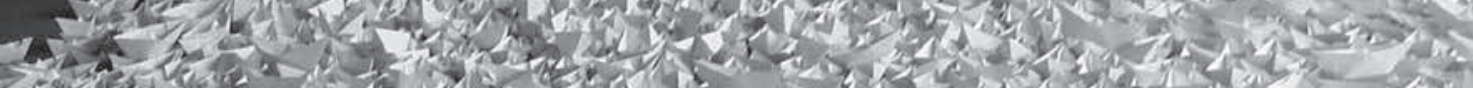

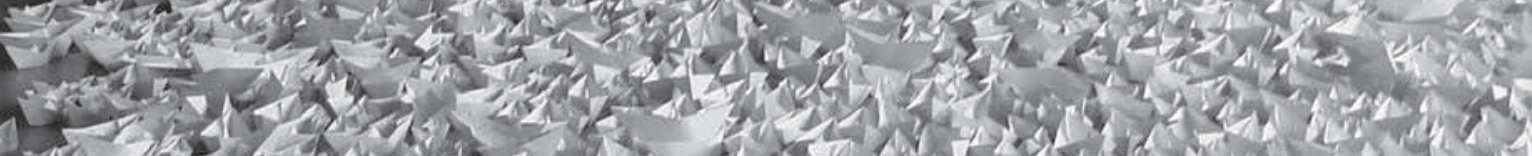
(1) 1 a

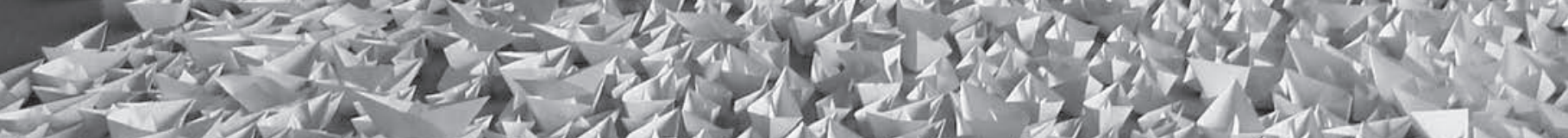
(1)

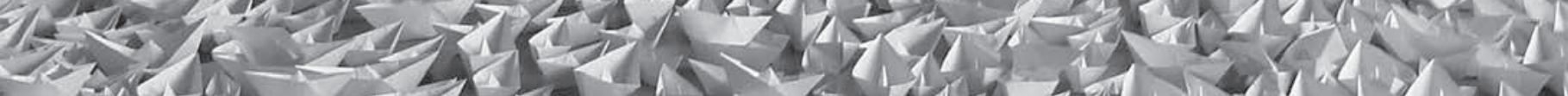

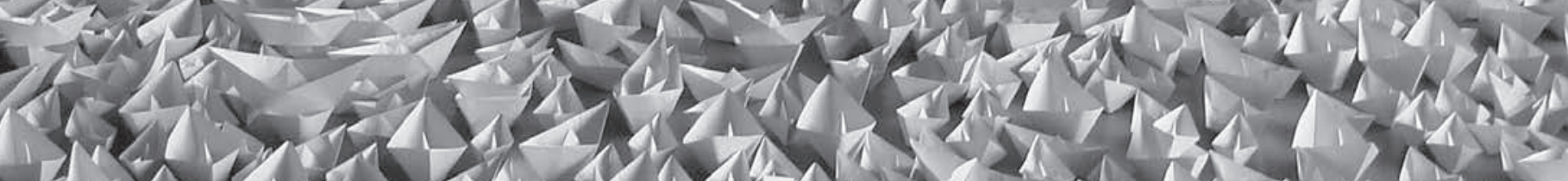
13 L (1)

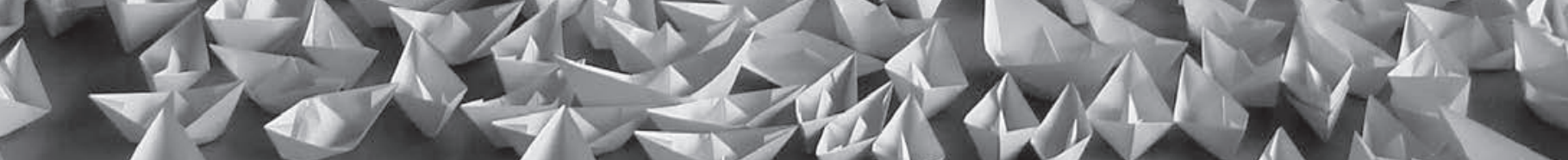

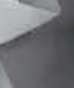

4
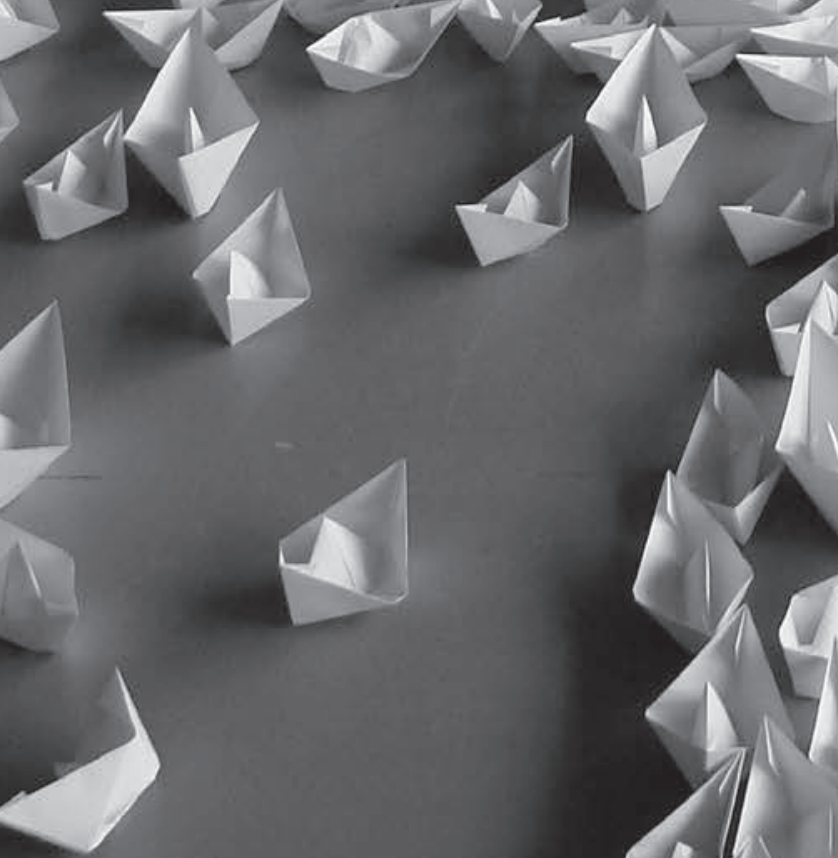


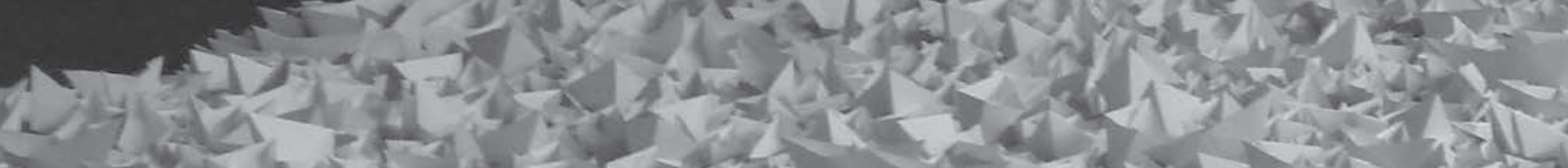

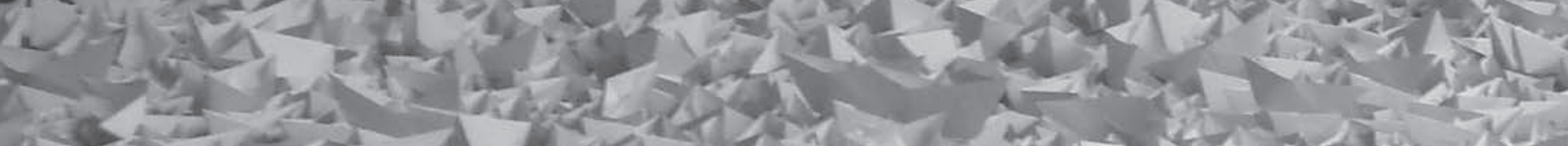

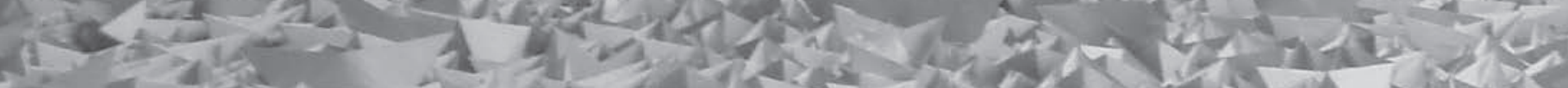

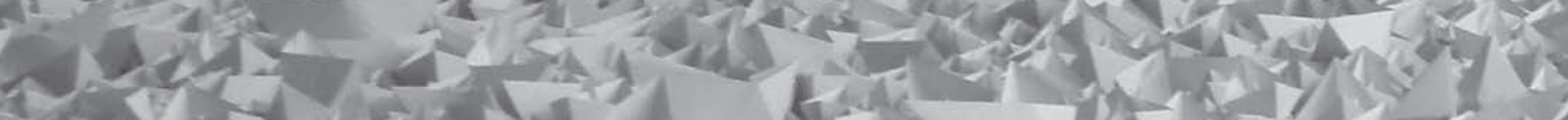

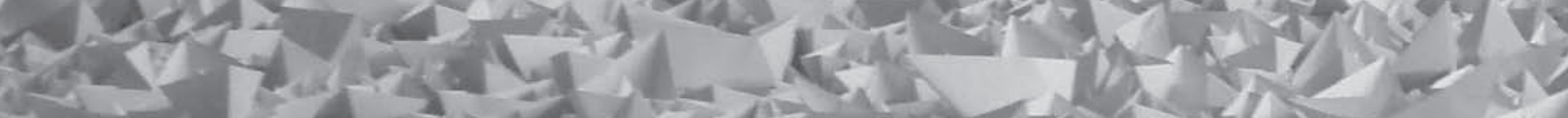

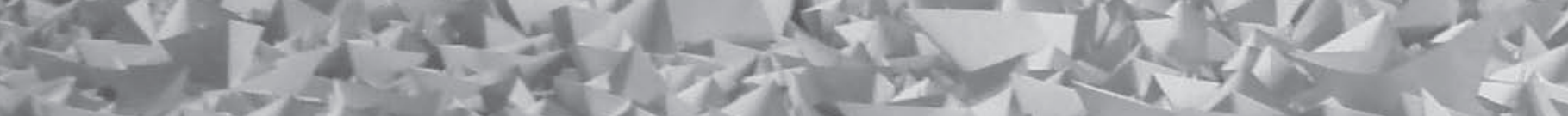

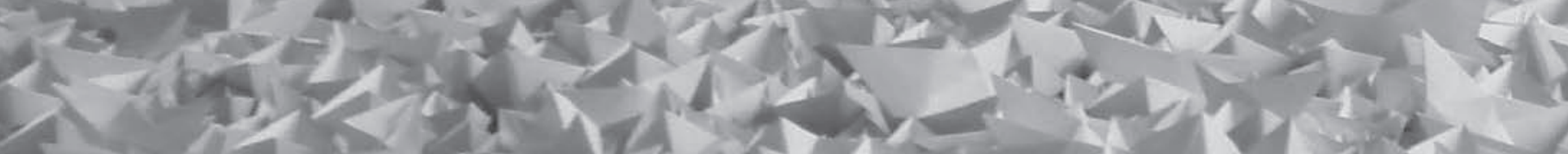

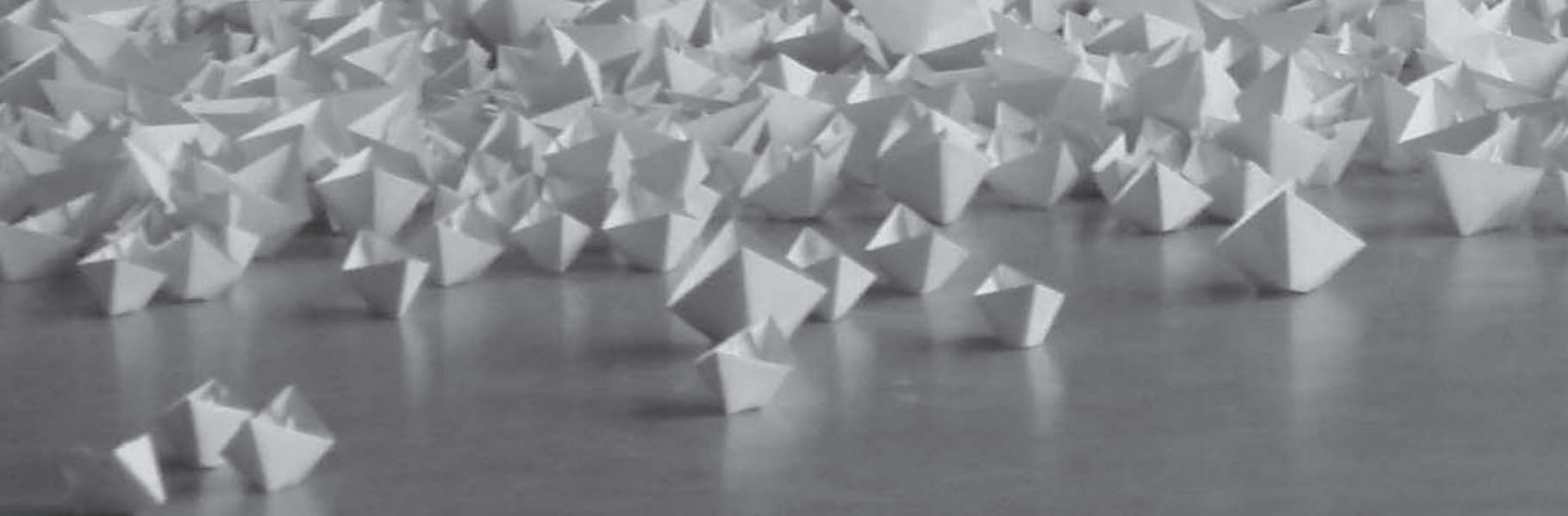


2.

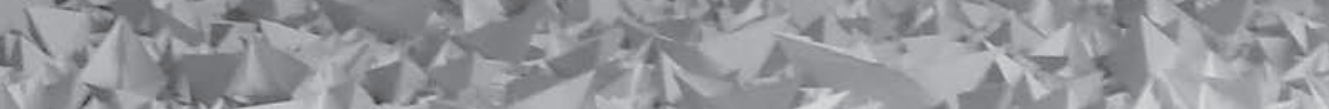

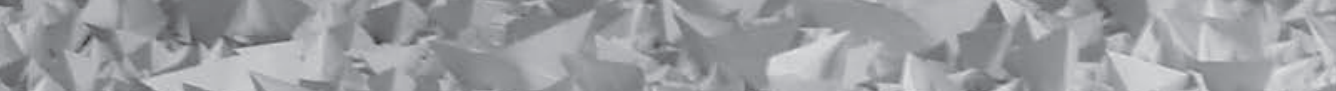

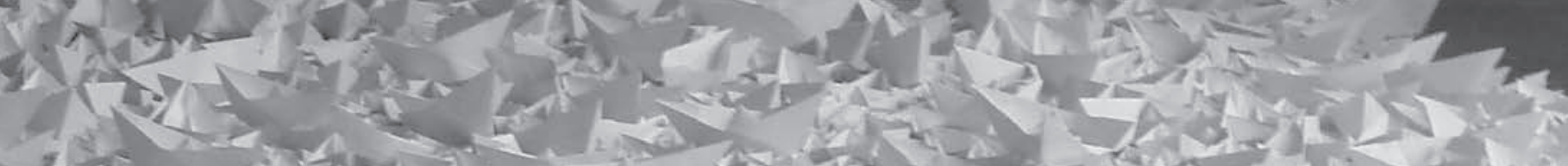

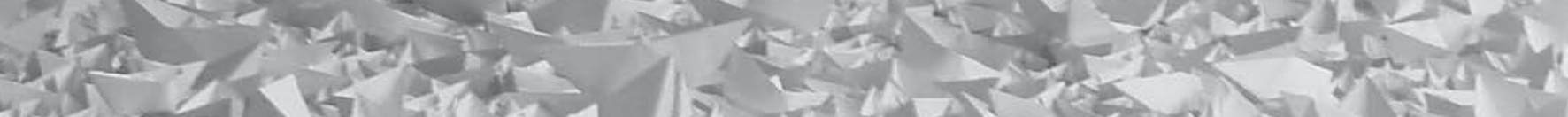

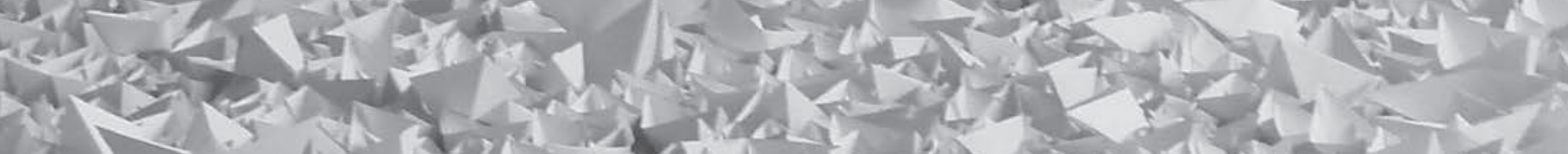

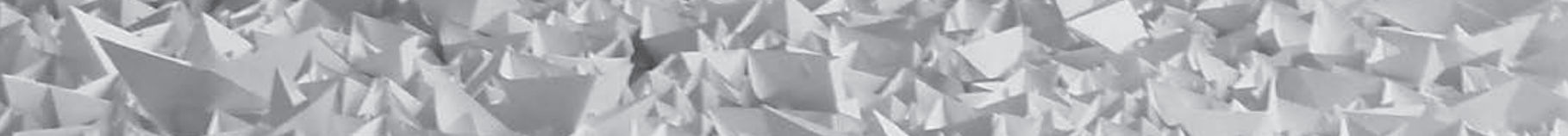

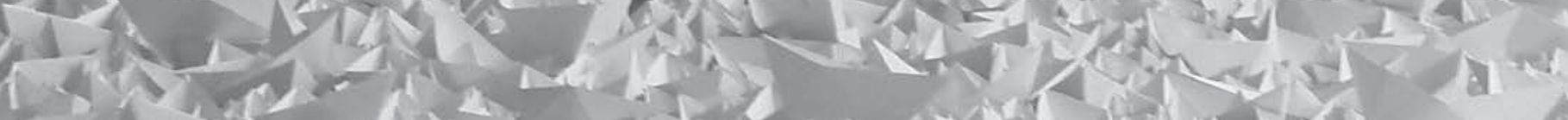

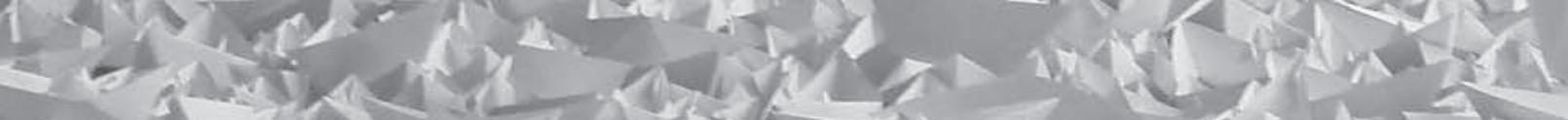

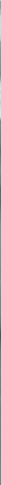




\section{Sandra Cinto}

Imitação da água 


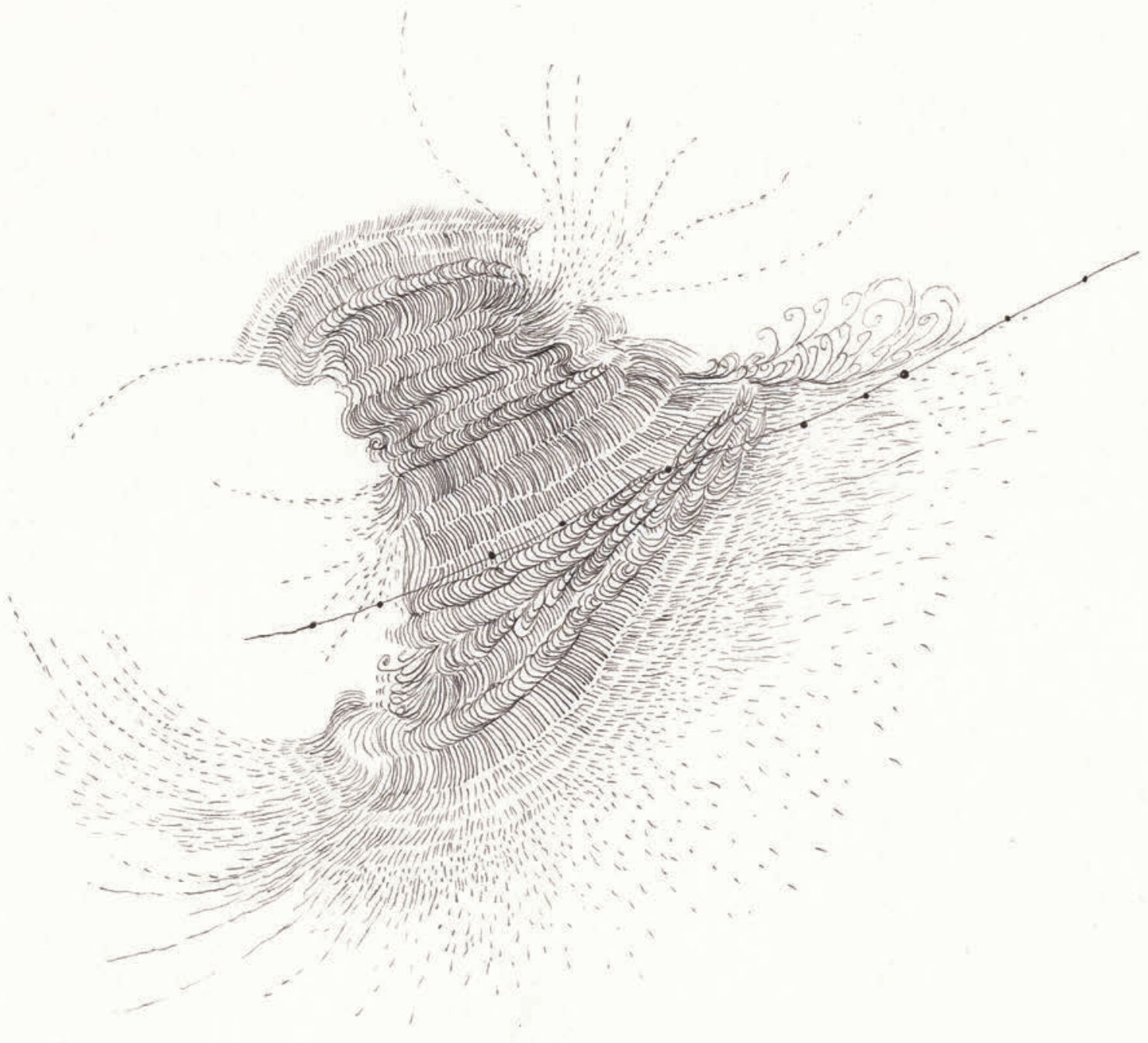




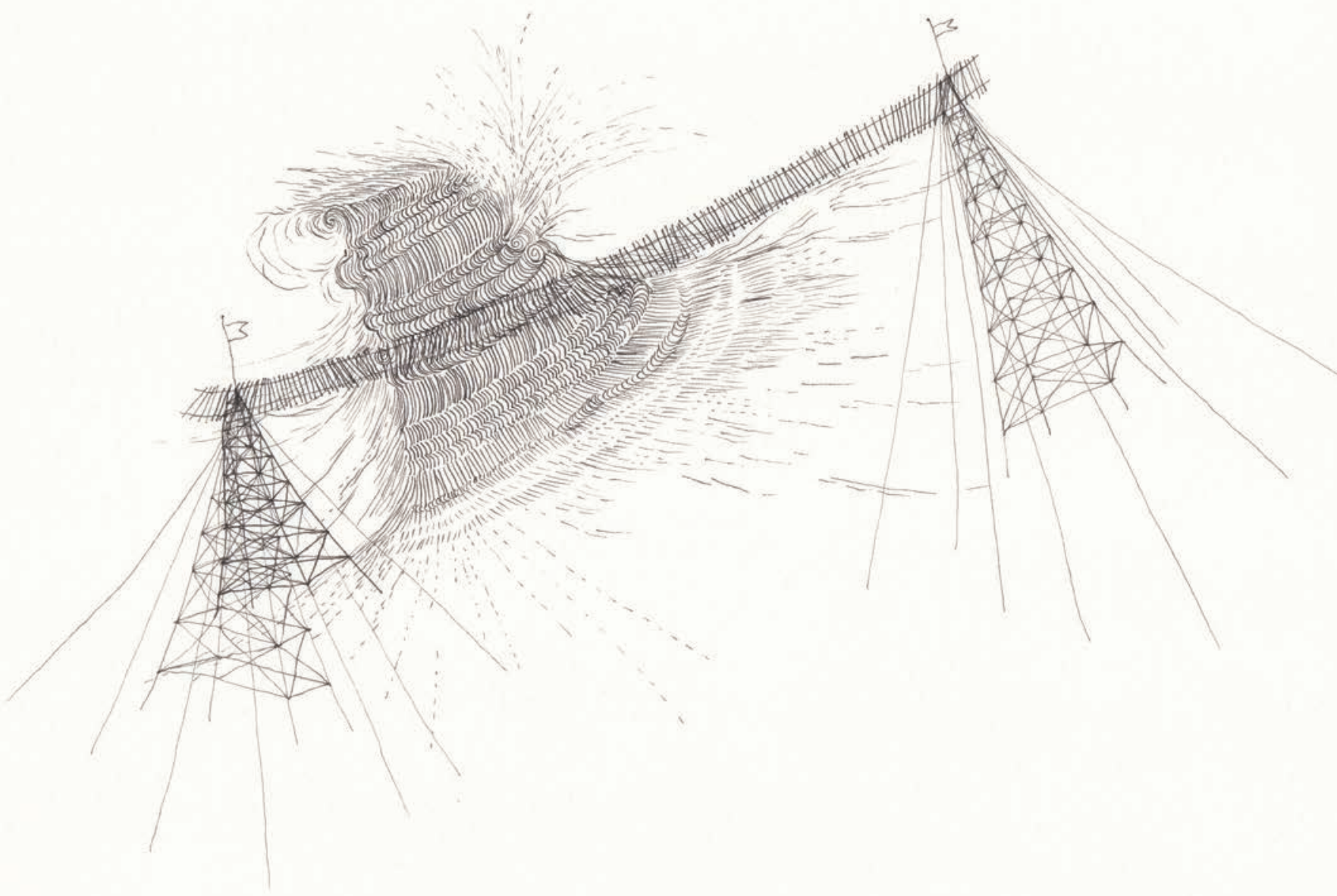




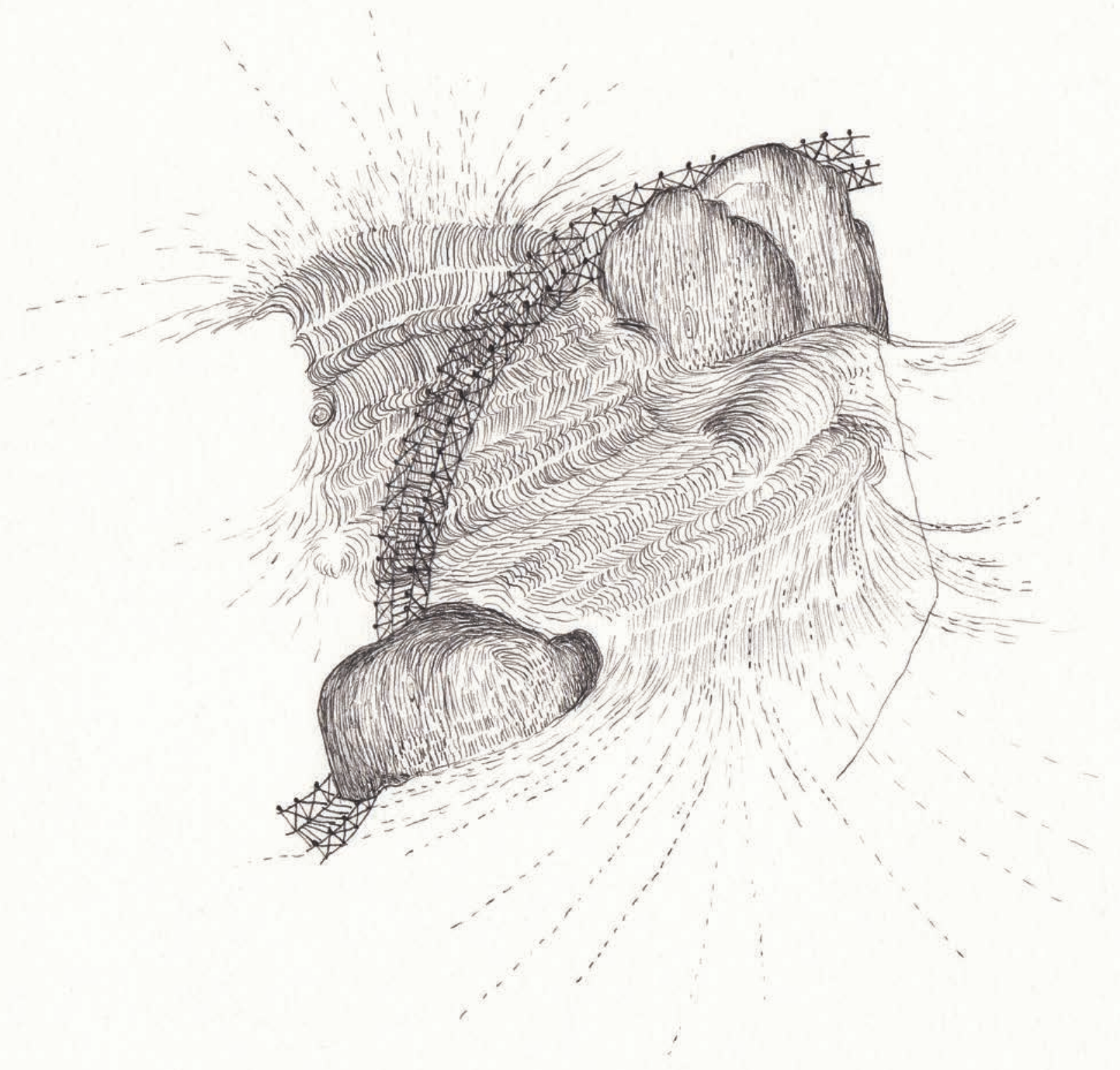




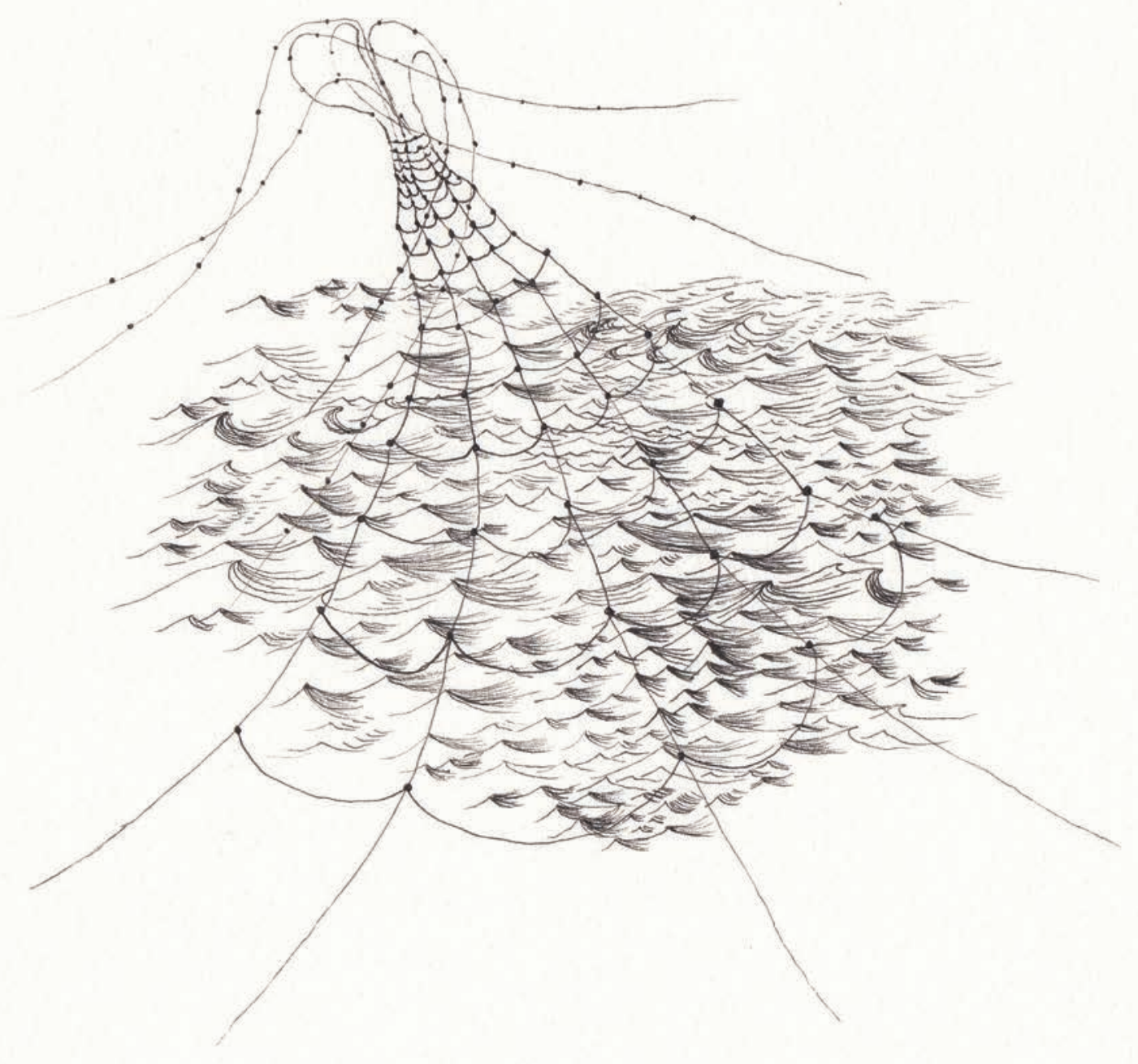




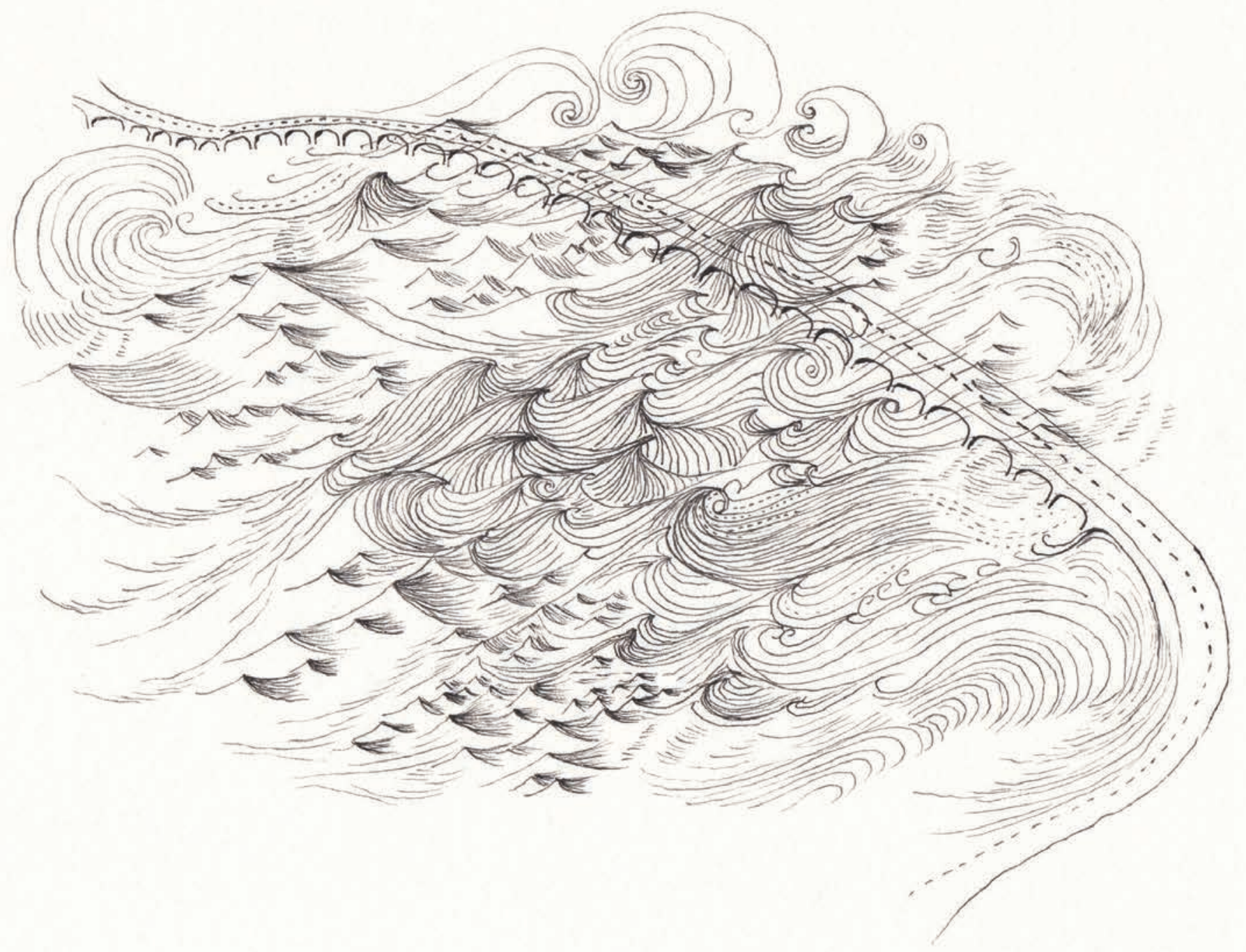




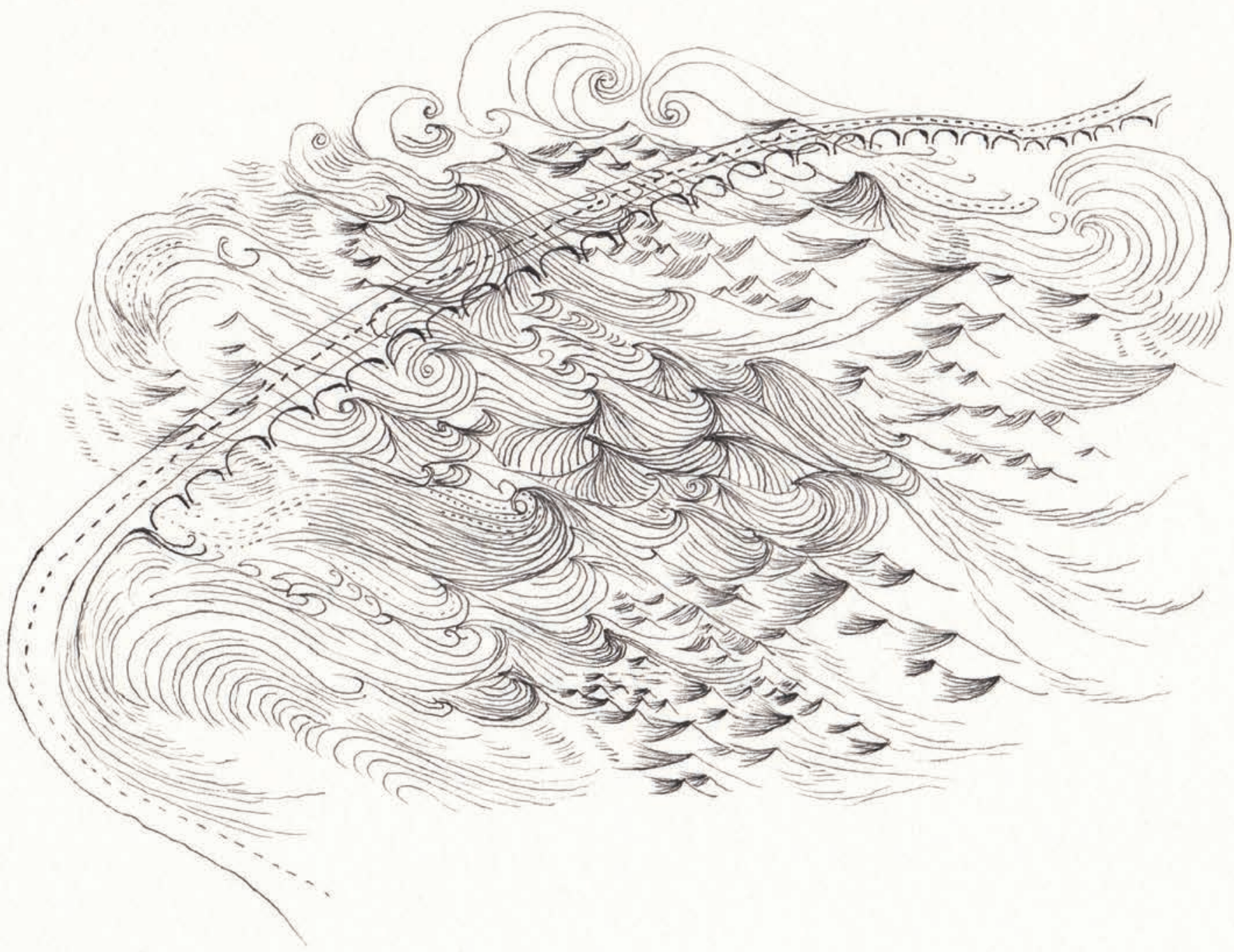


MLUMNA 
Albano Afonso

A Natureza 


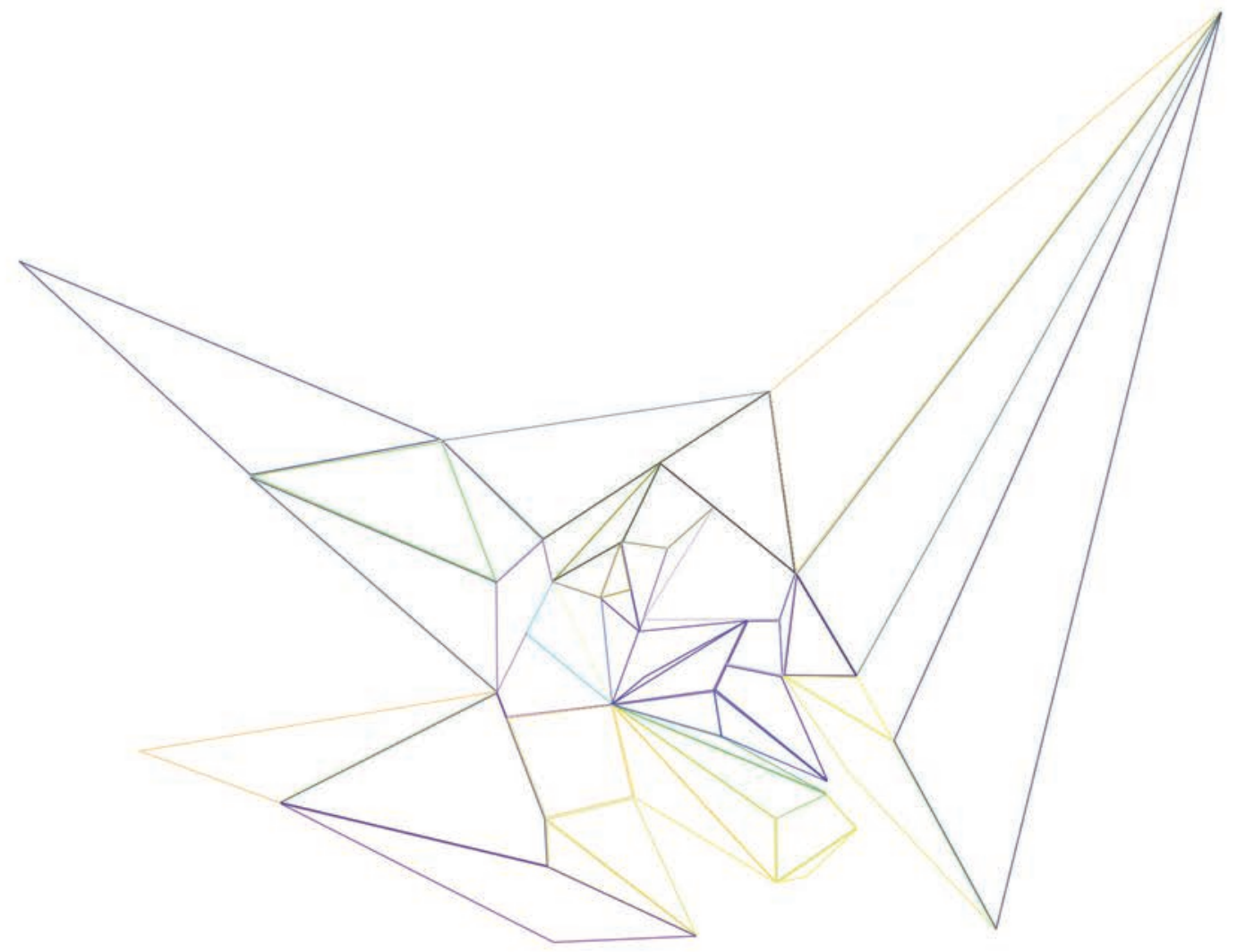




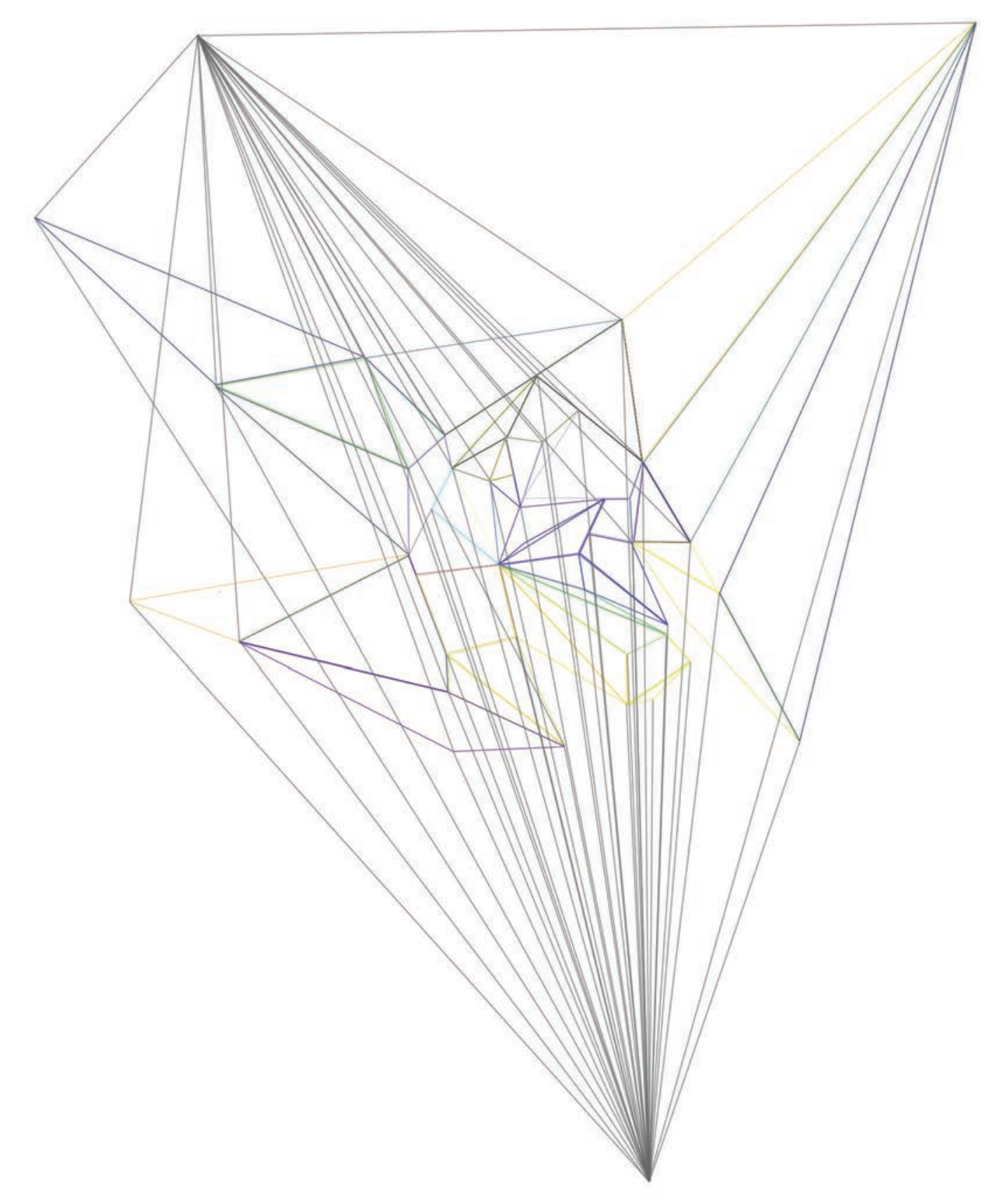




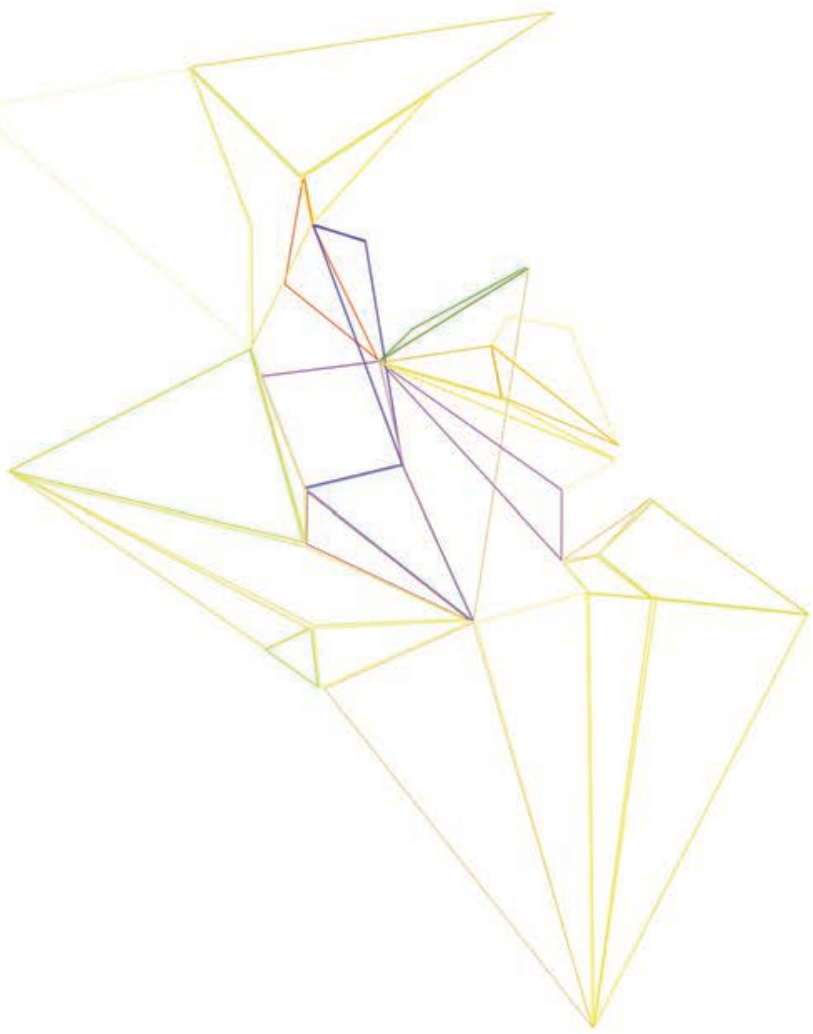




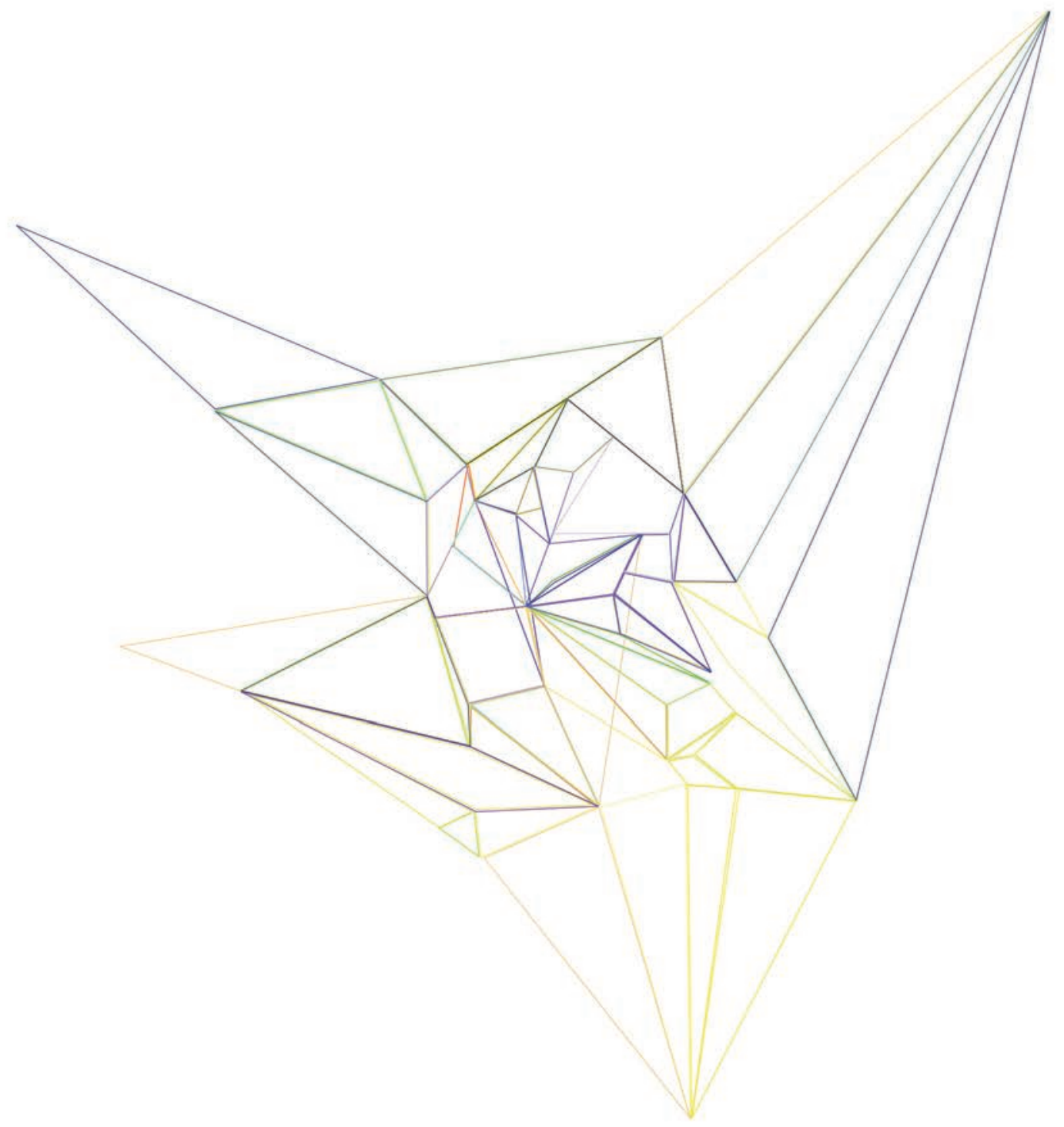




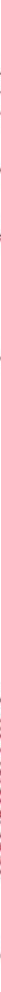




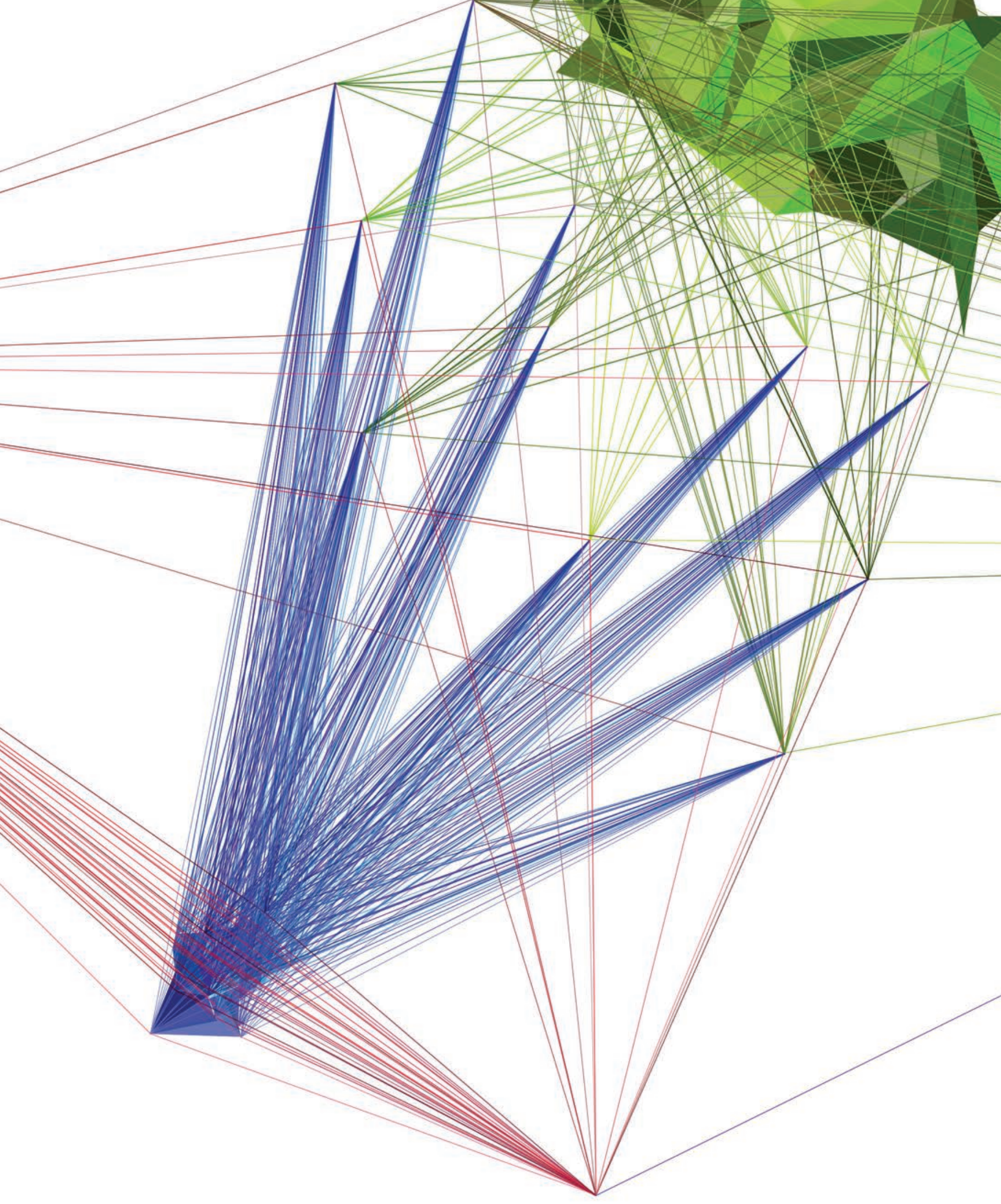





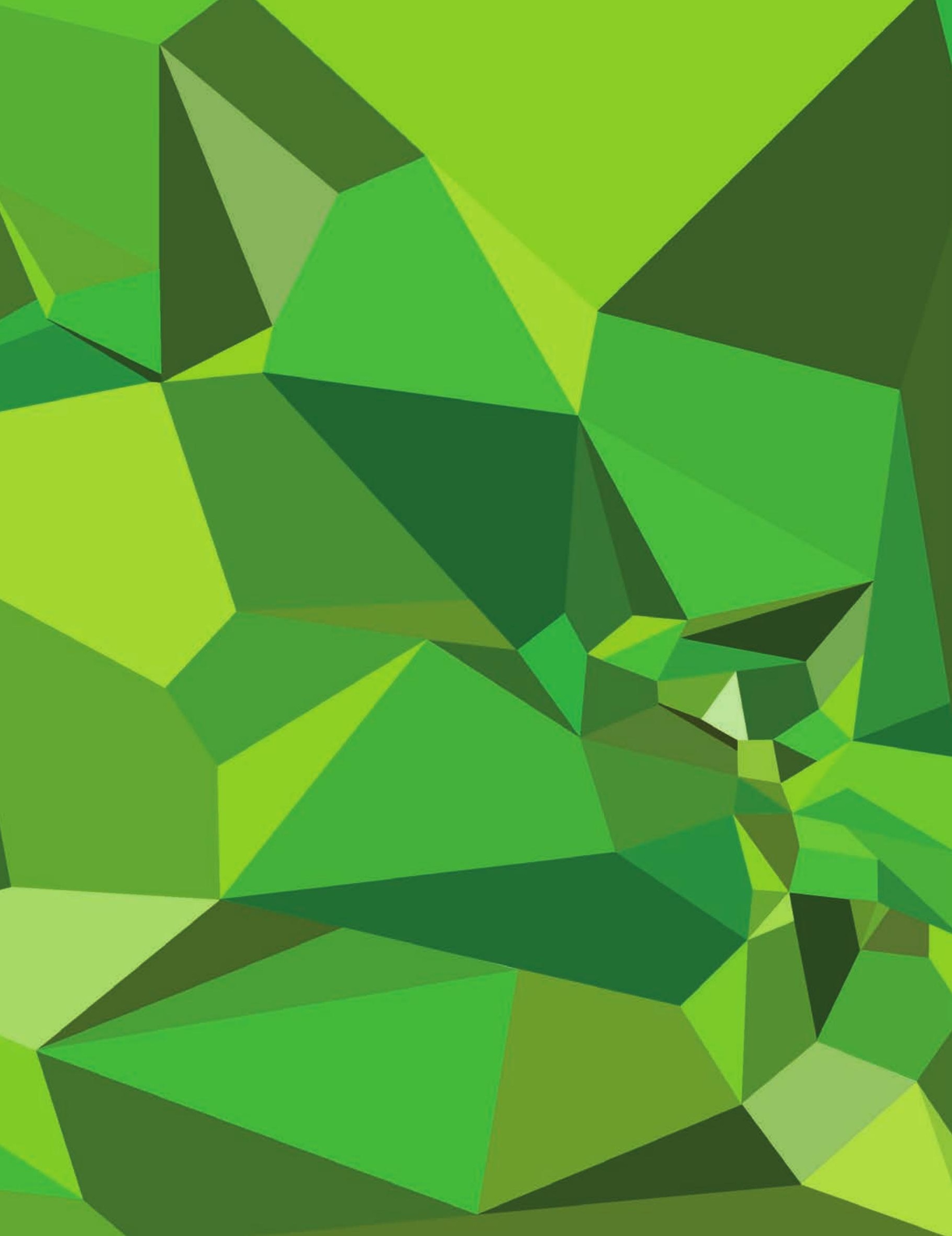

